\title{
Retro-Orbital Metastasis from Differentiated Thyroid Carcinoma in a Radioiodine Therapy-Naïve Patient: Any Lesson Learned?
}

\author{
P.C.N. Okere ${ }^{a}$ M. Tushar ${ }^{b}$ \\ a Department of Radiation Medicine, University of Nigeria Teaching Hospital, Ituku-Ozalla, Enugu, Nigeria; \\ ${ }^{b}$ Department of Nuclear Medicine, All India Institute of Medical Sciences, New Delhi, India
}

\section{Key Words}

Radioiodine therapy · Follicular thyroid carcinoma •

Retro-orbital metastasis $\cdot$ Diplopia

\begin{abstract}
Objective: To present the case of a radioiodine therapy-naïve thyroid cancer patient with postthyroidectomy diplopia.

Clinical Presentation and Intervention: A 63-year-old male patient presented with goiter. Histology performed after thyroidectomy proved follicular thyroid cancer. Without ${ }^{131}$ I therapy, diplopia occurred from metastasis to the right medial rectus muscle. Improvement followed after one therapy dose of ${ }^{131}$ I. Conclusion: Postoperative radioiodine was important in managing this patient with differentiated thyroid cancer. This case showed that retro-orbital metastasis should be considered as a differential diagnosis in a patient with thyroid cancer who presents with unilateral diplopia.
\end{abstract}

Copyright $\odot 2012$ S. Karger AG, Basel

\section{Introduction}

Follicular carcinomas of the thyroid are characterized by follicular differentiation but without the nuclear changes which are characteristic of papillary carcinoma [1]. These tumors are angioinvasive, unicentric and metastasize hematogenously. Orbital metastases are generally uncommon. Char et al. [2] found that 36 out of 612 orbital biopsies for suspected neoplasm yielded only $6 \%$ as metastatic.

\section{Case Report}

In February 1995 a 63 -year-old euthyroid male patient reported a neck swelling of 15 days' duration. Palpable nodules were found within both lobes of the thyroid gland but no cervical lymph nodes. A $185-\mathrm{MBq}(5-\mathrm{mCi}){ }^{99 \mathrm{~m}} \mathrm{Tc}$ pertechnetate scan showed intrathyroidal cold foci in the gland's right mid and lower poles. A $370-\mathrm{MBq}(10-\mathrm{mCi})$ pertechnetate thyroid angiography performed 3 days later confirmed a cold vascular thyroid nodule in the right lobe with a high probability for malignancy. Fineneedle aspiration cytology suggested a papillary carcinoma of the thyroid. A near-total thyroidectomy was carried out at the referral hospital. Permanent histologic sections of the thyroidectomy specimen measuring $7.5 \times 6.9 \mathrm{~cm}$ showed follicles with marked variations in size, many distended with colloid. There was extensive blood vessel and capsular invasion. The diagnosis was widely invasive follicular carcinoma of the thyroid. A diagnostic $185-\mathrm{MBq}(5-\mathrm{mCi}){ }^{131} \mathrm{I}$ whole-body scan (WBS) which was done 5 weeks later revealed minimal concentration of tracer over the thyroid bed. The patient was thereafter discharged on thyroid replacement therapy. A follow-up thyroglobulin (Tg) assay 1 year later was $>350 \mathrm{ng} / \mathrm{ml}$. This high titer spurred another diagnostic $185-\mathrm{MBq}(5-\mathrm{mCi}){ }^{131} \mathrm{I}$ WBS which did not show any difference in uptake from the previous diagnostic scan. Also, no anti-Tg antibody was detected.

\section{KARGER}

Fax +4161306 1234

E-Mail karger@karger.ch

www.karger.com
(C) 2012 S. Karger AG, Basel

$1011-7571 / 12 / 0216-0579 \$ 38.00 / 0$

Accessible online at:

www.karger.com/mpp
P.C.N. Okere

Department of Radiation Medicine

University of Nigeria Teaching Hospital

Ituku-Ozalla, Enugu (Nigeria)

E-Mail pcnokere@yahoo.com 
Fig. 1. CT scan of the head. The white arrow points to a fusiform enhancing mass (metastasis) in the belly of the right medial rectus muscle.

Fig. 2. $105-\mathrm{mCi}{ }^{131} \mathrm{I}$ posttherapy scan. The black arrow points to a right orbital concentration of tracer caused by a thyroid metastatic deposit in the medial rectus muscle. The white arrow points to remnant thyroid bed activity.
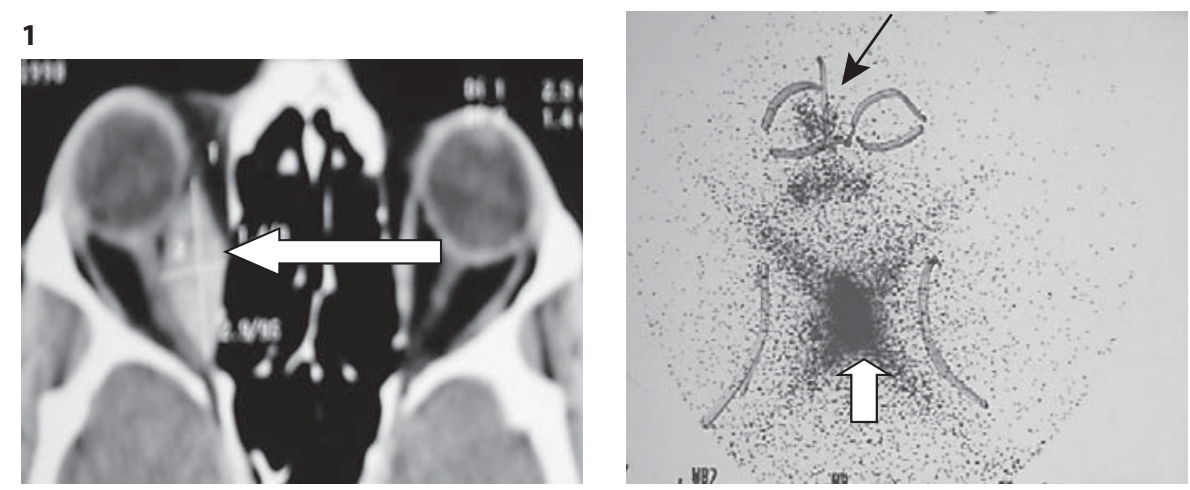

In January 1997, the patient complained of double vision in the right eye prompting the suspicion of thyroid cancer metastasis. However, surprisingly there was no elevation of Tg. A cranial computerized tomography (CT) scan was done in January 1998 due to worsening symptoms and revealed a brightly-enhancing fusiform intraorbital deposit in the belly of the right medial rectus muscle (fig. 1) measuring $2.9 \times 1.4 \mathrm{~cm}$. This was suspected to be a metastatic deposit and the patient was thereafter referred to the Department of Nuclear Medicine for possible radioiodine treatment. Approximately 2 months after the CT examination, the patient received the first of two doses of radioiodine-131, $3.885 \mathrm{MBq}$ $(105 \mathrm{mCi})$, and 10 months later another $3.70 \mathrm{MBq}(100 \mathrm{mCi})$. While the first posttherapy scan (fig. 2) showed dense remnant activity as well as a focus of activity in the right orbit, none of these were seen after the second scan, thus suggesting successful ablation of remnant as well as the orbital metastasis. Follow-up CT scans up to April 2003 showed reduction in lesion thickness from the initial 1.4 to $0.59 \mathrm{~cm}$. Serum Tg was undetectable and the patient no longer has diplopia.

\section{Discussion}

In this case, the thyroid cancer spread to the orbit although there are reports that claim orbital metastasis from thyroid cancer is rare [3,4]. Our case confirms a previous report that all thyroid cancers can spread to the orbit [5]. Since most differentiated thyroid cancer lesions are radioiodine-avid [6], our patient should have received this treatment after thyroidectomy as this would have decreased the chances of later metastatic disease. This case also showed that our patient, without any attempt to surgically excise an otherwise inaccessible retro-orbital metastatic focus, made rapid recovery after only the first therapy dose. Expert opinion [7] supports the postoperative use of radioiodine in a patient like ours who clearly had clinical and histological risk-conferring factors including his male gender, age $>45$ years and an aggressive follicular cancer at TNM stage III. It is therefore not sur- prising that the patient in the absence of radioiodine therapy progressed to metastatic disease. Radioiodine in therapy doses not only ablates remnant tumor, it also has the potential of revealing in the posttherapy WBS functioning locoregional and distant metastases even when these are yet subclinical. A previous report [8] had revealed unsuspected additional metastases in $10-26 \%$ of patients scanned following high-dose radioiodine treatment compared to lower-dose diagnostic scans. Thus the presence of competing follicular cells in the thyroid bed remnant may explain why the lower-dose diagnostic WBS failed to reveal the orbital focus.

Normal and neoplastic follicular cells elaborate $\mathrm{Tg}$, which should therefore not be detectable in patients who have undergone total thyroid ablation [9]. This is a clear benefit of postthyroidectomy radioiodine ablation which did not initially accrue to our patient. Therefore, in the presence of thyroid remnants, the use and the sensitivity of $\mathrm{Tg}$ as a marker of persistent or recurrent disease was questionable and uninformative.

Diplopia as a clinical presentation in patients with metastatic orbitopathy from thyroid carcinoma was previously reported $[2,4]$ and isolated involvement of an ocular muscle as seen in our patient has been found to be uncommon.

\section{Conclusion}

In this initially radioiodine therapy-naïve patient with differentiated thyroid cancer, the institution of radioiodine therapy was useful in the management of the disease including the diplopia resulting from the retro-orbital metastasis. 


\section{References}

1 Headinger C, Williams ED, Sobin LH: Histological Typing of Thyroid Tumors, 2nd ed. International Histological Classification of Tumours, No 11. Berlin, Springer, 1988.

$>2$ Char DH, Miller T, Kroll S: Orbital metastases: diagnosis and course. Br J Ophthalmol 1997;81:386-390.

3 Basu S, Nair N, Aravind N: Unilateral proptosis with thyrotoxicosis resulting from solitary retroorbital soft tissue metastasis from follicular carcinoma thyroid. Clin Nucl Med 2001;26:136-138.
4 Henderson JW: Orbital Tumors, ed 3. New York, Raven Press, 1994, pp 361-376.

5 Howden JO, Kean AM, Ghabrial R: Oral radioactive iodine for the treatment of orbital metastasis of carcinoma of the thyroid. Asian J Ophthalmol 2006;8:205-207.

6 Sherman SI: Thyroid carcinoma. Lancet 2003;361:501-511.

7 van Heerden JA, Hay ID, Goellner JR, Salomao D, Ebersold JR, Bergstralh EJ, Grant CS Follicular thyroid carcinoma with capsular invasion alone: a nonthreatening malignancy. Surgery 1992;112:1130-1136.
Fatourechi V, Hay ID, Mullan BP, Wiseman GA, Eghbali-Fatourechi GZ, Thorson LM, Gorman CA: Are posttherapy radioiodine scans informative and do they influence subsequent therapy of patients with differentiated thyroid cancer? Thyroid 2000;10:573577.

9 Van Herle AJ, Uller RP, Mathews NL, Brown $\mathrm{J}$ : Radioimmunoassay for measurement of thyroglobulin in human subjects. J Clin Invest $1973 ; 52: 1320-1327$. 